\title{
Studies on the expansion characteristics of the granular bed present in EGSB bioreactors
}

\author{
Yong-Hong Liu" ${ }^{1 *}$, Yan-Ling He ${ }^{1}$, Shu-Cheng Yang ${ }^{1}$ and Chun-Jiang An ${ }^{1}$ \\ ${ }^{1}$ Department of Environmental Engineering, Xi'an Jiaotong University, Xi'an, 710049, P.R.China \\ ${ }^{2}$ Department of Environmental Engineering, Xi'an University of Engineering Science and Technology, Xi'an, 710048, P.R.China
}

\begin{abstract}
In this study, the expansion characteristics of an anaerobic granular bed in EGSB reactors based on terminal settling velocity study of the granules and the Richardson-Zaki equation (1954) have been investigated. The settling velocity study shows that the mean settling velocity of the granules is in accordance with the Allen formula because the settling process falls within the intermediate flow regime range $\left(1<\mathrm{Re}_{t}<110\right)$ rather than in the laminar flow regime range; the bed expansion study based on the above conclusion is found to be similar to that suggested by the Richardson-Zaki equation. The validity of the settling velocity model is verified by using the operating parameters of several full-scale anaerobic reactors with an average relative error of $3.77 \%$, and the bed expansion data obtained from two laboratory-scale reactors are used to test the correlation with an average relative error of $2.64 \%$ and $4.57 \%$ respectively. Moreover, it could be a theoretical method to propose a suitable value of Vup during different operation periods of an EGSB system.
\end{abstract}

Keywords: UASB, EGSB, granular bed expansion, mean settling velocity, modelling, Richardson-Zaki equation

\section{Notation}

$d_{\mathrm{p}} \quad$ granule diameter by wet sieving $(\mathrm{m})$

$\mathrm{g} \quad$ gravitational acceleration $\left(\mathrm{m} \cdot \mathrm{s}^{-2}\right)$

$H \quad$ bed-expansion height (m)

$H_{0} \quad$ initial bed height (m)

$n \quad$ expansion index

$\mathrm{Re}_{t} \quad$ Reynolds number at terminal velocity

$u$ mean settling velocity of the granules $(\mathrm{m} / \mathrm{h})$

Vup upward liquid velocity $(\mathrm{m} / \mathrm{h})$

$\mu \quad$ the viscosity of wastewater (Pa.s)

$\varepsilon_{0} \quad$ preliminary bed voidage

$E$ bed voidage

$\eta \quad$ bed expansion

$\rho \quad$ the density of wastewater $\left(\mathrm{kg} \cdot \mathrm{m}^{-3}\right)$

$\rho_{\mathrm{p}} \quad$ the density of the granules $\left(\mathrm{kg} \cdot \mathrm{m}^{-3}\right)$

\section{Introduction}

The expanded granular sludge bed (EGSB) reactor, a novel variation on the upflow anaerobic sludge blanket reactor (UASB) concept in combination with the anaerobic fluidised-bed reactor (AFBR), has recently experienced tremendous growth. Although UASB is still the predominant technology in use, EGSB-type processes are now gaining more popularity driven by economics (Frankin, 2001).

Similar to UASB technology, the EGSB reactor relies on the self-immobilisation properties of micro-organisms and the

* To whom all correspondence should be addressed.

푤 +86 (29) 8266-3933; fax: +86 (29) 8266-4272;

e-mail: liuyhxa@hotmail.com

Received 19 August 2005; accepted in revised form 10 May 2006. development within the reactor of a granular biomass with good settling properties. Compared with conventional UASB reactors $(0.5$ to $2 \mathrm{~m} / \mathrm{h})$, the advantage of the EGSB system $(>4 \mathrm{~m} / \mathrm{h})$ is the significantly better contact between sludge and wastewater. So it is widely believed to be a potentially high-rate anaerobic reactor by experts from different countries (Seghezzo et al., 1998; Hulshoff et al., 2004).

The knowledge of the bed expansion plays an important role in the design and operation of an EGSB reactor, because it is the key point to reach a compromise between bed expansion and sludge washout, and the stability and performance of the EGSB system would be sensitive to the degree of expansion (Liu et al., 2002). Therefore, quantitative research on bed expansion in EGSB reactors is necessary, although few reports are found in the literature.

In fact, the bed expansion is closely related to the settling characteristics of the sludge, hence the settling characteristics of the granules have to be discussed first.

The mean settling velocity is generally used to evaluate the settling characteristics of the granules. Almost all previous work published suggests that the mean settling velocity of the granules is in accordance with Stokes' law because the settling process is in the laminar flow range (Hulshoff, 1989; Hu, 2003; Field, 2005), whilst others suggest that it is in accordance with the Allen formula because the settling process falls within the intermediate flow range (Wang, 2002). However, the settling characteristics of the granules have scarcely been discussed theoretically by the above workers.

To the best of our knowledge, there has been no report yet on the quantitative relationship of the bed expansion in EGSB reactors, partly due to the lack of an approved method to determine the settling velocity and $\mathrm{Re}_{t}$ of the granules.

The objective of this study is to focus on the bed expansion characteristics of EGSB reactors on the basis of settling velocity study of the granules. 


\section{Materials and methods}

\section{Experimental}

The density and diameter of samples sludge were measured experimentally with the methods given elsewhere (Hulshoff, 1989). The sludge particles were sequentially separated by using five stainless-steel sieves $(0.20,0.45,0.63,0.90$, and $2.00 \mathrm{~mm})$. Here the mean diameter by wet sieving is considered as the average equivalent diameter in the settling and bed-expansion processes.

To determine the settling velocity of the sludge we used a modified sedimentation balance which is a standard method developed by Paques BV, Balk, The Netherlands. The settling rates are determined by using a $2.5 \mathrm{~m}$ high settling column filled with tap water and are obtained from the evolution of the weight of the settled sludge as a function of the sedimentation time (Hulshoff, 1989).

Bed expansion experiments were conducted in two laboratory-scale EGSB reactors at $30^{\circ} \mathrm{C}$, and synthetic wastewater prepared by portable water and glucose was used to simulate the wastewater.

Reactor 1 (R1) had a working volume of $60 \ell$ with a height of $2 \mathrm{~m}$ and diameter of $0.2 \mathrm{~m}$, and the original bed height of the reactor was $0.445 \mathrm{~m}$. Sludge Sample 1 was obtained from a full-scale EGSB reactor $\left(275 \mathrm{~m}^{3}\right)$ treating starch wastewater in Yi-shui, Shandong province, China. Reactor 2 (R2) had a working volume of $14.8 \ell$ with a height of $1.8 \mathrm{~m}$ and a diameter of $0.09 \mathrm{~m}$, and original bed height of the reactor was $0.708 \mathrm{~m}$. Sludge Sample 2 was obtained from an existing UASB reactor in our laboratory.

The different heights of the sludge bed were recorded at the various upward velocities $(1,2,3,4,5,6,7,8,9,10 \mathrm{~m} / \mathrm{h})$ throughout the experiments.

\section{Model development}

\section{Terminal settling velocity model}

The settling velocity of the granules can be determined from the well-known force balance:

$$
u_{t}=\sqrt{\frac{4 g_{d_{p}}\left(\rho_{p}-\rho\right)}{3 \xi \rho}}
$$

In Eq. (1), the drag coefficient $\xi$ is a function of $\mathrm{Re}_{t}$ :

$$
\xi=\phi(\operatorname{Re} t)
$$

Assuming that the settling process of the granules is in the category of intermediate flow regime $\left(0.2<\operatorname{Re}_{t}<500\right), \xi$ is recommended as follows (Perry and Green, 1997):

$$
\xi=18.5 \operatorname{Re}_{t}^{-0.6}
$$

Then substituting Eq. (3) into Eq. (1), the settling velocity of granules calculated from Allen's law may be written as (in absence of the wall effects) (Liu et al., 2005):

$$
u_{t}=0.781\left[d_{p}{ }^{1.6}\left(\rho_{p}-\rho\right) / \rho^{0.4} \mu^{0.6}\right]^{0.714}
$$

The value of $\mathrm{Re}_{t}$ should be verified to check up the rationality of the assumption afterwards:

$$
\operatorname{Re}_{t}=\rho d_{p} u_{t} / \mu
$$

\section{Bed expansion model}

There are several papers dealing with sludge bed expansion, such as EGSB (Kato et al. 1994), AFBR (Setiadi, 1995), biofilm reactors (Nicolella, 1999), UASB (Leitao, 2004), and the anaerobic hybrid reactor (Saravanan, 2005). Although those reactors are actually three-phase systems and the biogas produced may have some influence on the bed expansion behaviour, it is suggested that those reactors should still be regarded as classic two-phase (solid-liquid) systems, since the above researchers found that the effect of the gas flow rate on the bed expansion is insignificant and the effect of biogas can be ignored without introducing an important error. On the other hand, it was also found that the biogas has little effect on expansion behaviour in our experiments. In conclusion, it is reasonable to describe the bed as a likely two-phase solid-liquid system.

The bed expansion data are generally reported and compared with numerical relationships in terms of bed voidage $\varepsilon$ as a function of fluid superficial velocity; convenient as it is, this representation has the disadvantage, particularly at high bed expansion. Hence, in our study these data will be generated by bed expansion of a granular bed.

In current studies, we focus on the bed expansion present in EGSB reactors, as a function of upward liquid velocity, with little attention on what is going on in the bed itself, such as gas production.

The experimental evidence published up to now suggests that bed expansion characteristics of a biological fluidised bed reactor can be well represented by the Richardson and Zaki correlation (Richardson and Zaki, 1954). Their relation is written as:

$$
u=u_{t} \varepsilon^{n}
$$

where the expansion index $n$ was found to be a function of Re only, whilst Richardson and Zaki recommended the following correlation:

$$
\begin{array}{ll}
n=4.65 & \operatorname{Re}_{t}<0.2 \\
n=4.4 \operatorname{Re}_{t}^{-0.03} & 0.2<\operatorname{Re}_{t}<1 \\
n=4.4 \operatorname{Re}_{t}^{-0.1} & 1<\operatorname{Re}_{t}<500 \\
n=2.4 & 500<\operatorname{Re}_{t}
\end{array}
$$

Correspondingly assuming that the settling process of the granules is in the category of intermediate flow regime, then the correlation for $n$ is written as:

$$
n=4.4 \mathrm{Re}_{t}^{-0.1}
$$

Substituting Eq. (7) into Eq. (6), the bed voidance can be written as:

$$
\varepsilon=e^{\frac{\ln \frac{u}{u t}}{4.4 \operatorname{Re}_{t}^{-0.1}}}
$$

The bed expansion $\eta$, which is defined as follows:

$$
\eta=\frac{H-H_{0}}{H_{0}} \times 100 \%
$$

The expanded bed height $\mathrm{H}$ data could be easily transformed to bed voidage by using the flow equation (Zhang, 2004):

$$
\eta=\frac{\varepsilon-\varepsilon_{0}}{1-\varepsilon} \times 100 \%
$$

where:

$\varepsilon_{0}$ is usually from 0.4 to 0.45 for nearly spherical particles, here it is taken as 0.4 .

Substituting Eq. (8) into Eq. (10), the bed expansion can now be written as: 


$$
\eta=\frac{e^{\frac{\ln \frac{u}{u t}}{4.4 \operatorname{Re}_{t}^{-0.1}}}-0.4}{1-e^{\frac{\ln \frac{u}{u t}}{4.4 \operatorname{Re}_{t}^{-0.1}}} \times 100 \%}
$$

Therefore, the bed expansion in EGSB reactors with different granular sludge under different liquid superficial velocities can be investigated.

Substituting Eq. (11) into Eq. (9), the expanded bed height under different operating conditions can also be calculated:

$$
H=H_{0}\left(\begin{array}{c}
1+\frac{e^{\frac{\ln \frac{u}{u t}}{4.4 \operatorname{Re}_{t}^{-0.1}}}-0.4}{1-e^{\frac{\ln \frac{u}{u t}}{4.4 \operatorname{Re}_{t}^{-0.1}}} \times 100 \%}
\end{array}\right)
$$

\section{Results and discussions}

Firstly, the theoretical method to determine the settling velocity and $\mathrm{Re}_{t}$ of the granules is developed. Secondly, experimental data of the bed expansion presented in EGSB reactors and the application of the bed expansion model are presented.

\section{Testing the terminal settling velocity model of anaerobic granular sludge}

Since the settling tests are conducted in a settling column filled with tap water, the viscosity of water at room temperature $\left(10^{-3} \mathrm{~Pa} . \mathrm{s}\right)$ will be used in the present calculations.

\section{Simulation analysis of the settling velocity model}

In general, the granular diameter ranges between 0.5 and $5 \mathrm{~mm}$, but the mean diameter of sludge granules in full-scale installations typically ranges between 1 and $3 \mathrm{~mm}$. So the diameter of the granules ranges between 0.3 and $2.5 \mathrm{~mm}$ in our simulation analysis.

On the other hand, larger sludge granules have low density whose values range typically between 1000 and $1050 \mathrm{~kg} \cdot \mathrm{m}^{-3}$ (Lens et al., 1998), so they are respectively $1010,1020,1030$, $1040,1050 \mathrm{~kg} \cdot \mathrm{m}^{-3}$ in our calculation. Additionally, $\rho$ is taken as $1000 \mathrm{~kg} \cdot \mathrm{m}^{-3}$.
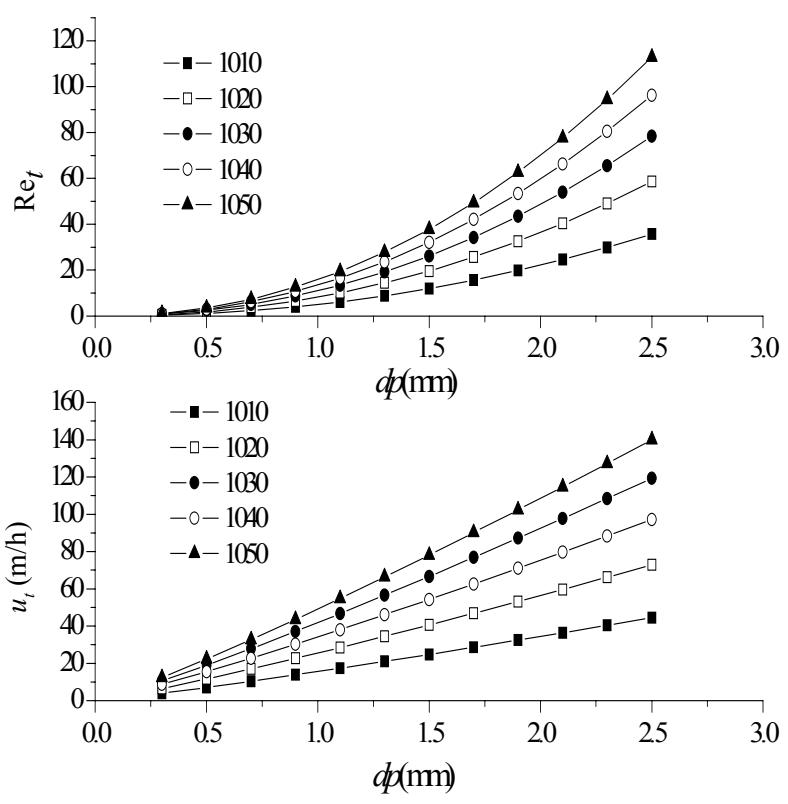

Figure 1

Calculated settling velocity and $R e_{t}$ of the granules

The calculated settling velocities and $\mathrm{Re}_{t}$ of the granules with different density versus mean diameter obtained from Eqs. (4) and (5) are shown in Fig. 1.

Figure 1 shows that settling velocities are in the range of $4 \sim 140 \mathrm{~m} / \mathrm{h}$. For most sludge granules, the calculated settling velocities are above $10 \mathrm{~m} / \mathrm{h}$ so that high hydraulic loads can be applied without considerable sludge washout in high-rate anaerobic reactors.

On the other hand, for most sludge granules, the corresponding $\operatorname{Re}_{t}$ are from 1 to 110 , as shown in Fig. 1. Briefly, it demonstrates theoretically that the settling process of the sludge is in the intermediate flow regime category while the mean settling velocity should be calculated with Eq. (4).

\section{Verification of terminal settling velocity model}

In the present study, in order to verify the validity of the above model, settling velocities and $\mathrm{Re}_{t}$ of nine samples between calculated and measured values are shown in Table 1 (Liu et al., 2005b; Hulshoff, 1989).

\begin{tabular}{|l|l|l|l|l|}
\hline \multicolumn{5}{|c|}{ TABLE 1 } \\
Measured settling velocities and Reynolds number at terminal \\
velocity of nine samples
\end{tabular}

a. Starch wastewater (EGSB-granules granules in Zhu-cheng, Shandong Province, China)

b. Beet sugar factory (Suiker Unie, Roosendaal, The Netherlands)

c. Starch wastewater (EGSB-granules in Yi-shui, Shandong Province, China)

d. Starch wastewater (UASB-granules in Yi-shui, Shandong Province, China)

e. Starch wastewater (UASB-granules in Zhu-cheng, Shandong Province, China)

f. Distillery wastewater (Nedalco, Bergen opZoom, The Netherlands)

g. Potato processing plant (Aviko, Steenderen, The Netherland)

h. Beet sugar factory (Central Suiker Maatschappij, Breda, The Netherlands)

$i$. Wastepaper plant (Papierfabrick Roermond, The Netherlands) 


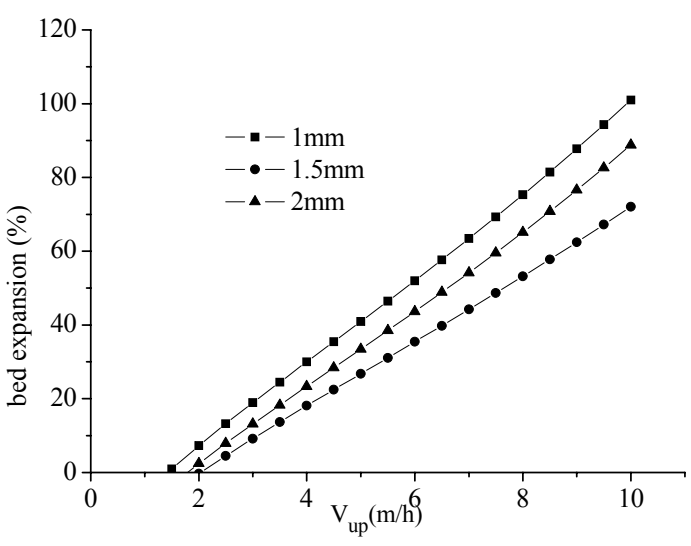

Figure 2

The mathematical analysis between bed expansion and upward liquid velocity

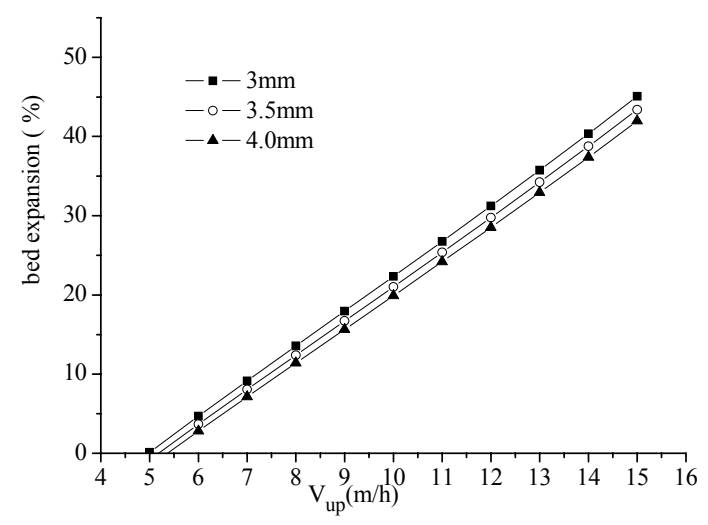

Figure 3

The mathematical analysis between bed expansion and Vup in a Biobed ${ }^{\circledR} E G S B$ reactor

Table 1 shows that the average relative errors of $u$ and Re between calculated and experimental values were $3.77 \%$ and $3.2 \%$ respectively. The error of the proposed model may be due to the wall effects, gas production during settling processes and so on. It implies that those factors could be disregarded when calculating the mean settling velocity of the granules.

\section{Bed expansion present in EGSB reactors}

Based on the aforementioned results and studies, the bed expansion present in EGSB reactors can be studied by Eq. (11). The viscosity of wastewater $\mu$ varies with the temperature and it has been reported that the value is approximately $8.6 \times 10^{-4} \mathrm{~Pa}$.s at $30^{\circ} \mathrm{C}$ in EGSB reactors (EC Pireset al., 2000; Mahmoud et al., 2003 ), thus we use the value of $8.6 \times 10^{-4} \mathrm{~Pa}$.s in this section for the purpose of consistency.

\section{Simulation analysis of the expansion model}

Here we select the upward liquid velocity from 0 to $10 \mathrm{~m} / \mathrm{h}$ in our simulation analysis. Moreover, while $d_{p}$ is $1 \mathrm{~mm}, 1.5 \mathrm{~mm}$ and $2.0 \mathrm{~mm}$, the corresponding density of the granules is 1030 $\mathrm{kg} \cdot \mathrm{m}^{-3}, 1020 \mathrm{~kg} \cdot \mathrm{m}^{-3}, 1010 \mathrm{~kg} \cdot \mathrm{m}^{-3}$ respectively. Additionally, $\rho$ is taken as $1000 \mathrm{~kg} \cdot \mathrm{m}^{-3}$.

The bed expansion data under different upward liquid velocities with different granule size calculated by Eq. (11) are shown in Fig. 2.

The bed expansion with increasing velocity is observed in Fig. 2. The predicted bed expansion is very low when Vup

\begin{tabular}{|c|c|c|c|c|}
\hline \multicolumn{5}{|c|}{$\begin{array}{c}\text { TABLE } 2 \\
\text { Bed expansion values calculated from the } \\
\text { model compared with actual values }\end{array}$} \\
\hline \multirow{3}{*}{$\begin{array}{l}V_{u p} \\
(\mathrm{~m} / \mathrm{h})\end{array}$} & \multicolumn{4}{|c|}{ Bed expansion (\%) } \\
\hline & Reactor 1 & & Reactor 2 & \\
\hline & \begin{tabular}{|l|}
$\begin{array}{l}\text { Calculated } \\
\text { results }\end{array}$ \\
\end{tabular} & $\begin{array}{l}\text { Experimental } \\
\text { results }\end{array}$ & $\begin{array}{l}\text { Calculated } \\
\text { results }\end{array}$ & $\begin{array}{l}\text { Experimental } \\
\text { results }\end{array}$ \\
\hline 1 & 0 & 0 & 0 & 3 \\
\hline 2 & 0 & 0 & 1.34 & 5.8 \\
\hline 3 & 3.61 & 2 & 11.0 & 14.5 \\
\hline 4 & \begin{tabular}{|l|}
11.1 \\
\end{tabular} & 9 & 20 & 26.6 \\
\hline 5 & 18.2 & 18.6 & 28.8 & 35 \\
\hline 6 & 25.2 & 23.6 & 37.5 & 41.9 \\
\hline 7 & 32.1 & 32.1 & 46.3 & 51.1 \\
\hline 8 & 39.1 & 36.5 & 55.2 & 58.3 \\
\hline 9 & 46.2 & 51.5 & 64.4 & 64.1 \\
\hline 10 & 53.4 & 57.7 & 73.9 & 77.4 \\
\hline
\end{tabular}

is lower than $2 \mathrm{~m} / \mathrm{h}$, and then the bed behaves as a static bed, e.g. those in UASB reactors $(<2 \mathrm{~m} / \mathrm{h})$; the predicted $\eta$ is nearly $0 \sim 50 \%$ when Vup ranges from 2 to $6 \mathrm{~m} / \mathrm{h}$ and the predicted $\eta$ is nearly $50 \sim 100 \%$ when $V u p$ ranges from 6 to $10 \mathrm{~m} / \mathrm{h}$. It implies that the bed will begin to expand when Vup exceeds $2 \mathrm{~m} / \mathrm{h}$.

Figure 2 also reveals that the predicted $\eta$ will exceed $20 \%$ when Vup is above $4 \mathrm{~m} / \mathrm{h}$. It is consistent with the main characteristics of EGSB reactors ( $>4 \mathrm{~m} / \mathrm{h}$ ) (Seghezzoet al., 1998).

In the design and start-up of AFBR, Marin suggested that the degree of bed expansion should be controlled in the range of 20 40\% (Marin et al., 1999). If we accept his proposal here, one conclusion that can be drawn is that the value of Vup necessary to maintain an expansion of $20 \sim 40 \%$ is in the range of $3 \sim 7 \mathrm{~m} / \mathrm{h}$ (as shown in Fig. 2). These results are in good agreement with the published results of many previous studies on EGSB reactors (Kato et al. 1994; Hwu et al., 1998; Jeison et al., 1999).

\section{Verification of expansion model using experimental data}

According to the methods mentioned above, the mean diameter of Sample 1 is $1.227 \mathrm{~mm}, \rho_{\mathrm{p}} 1040 \mathrm{~kg} \cdot \mathrm{m}^{-3}$, and $\rho 1002.6 \mathrm{~kg} \cdot \mathrm{m}^{-3}$. The mean diameter of Sample 2 is $0.9696 \mathrm{~mm}, \rho_{\mathrm{p}} 1045 \mathrm{~kg} \cdot \mathrm{m}^{-3}$, and $\rho 1002.6 \mathrm{~kg} \cdot \mathrm{m}^{-3}$.

Based on those physical parameters and the variations of the bed height, the comparison of the bed expansion between calculated and measured values is shown in Table 2.

As shown in Table 2, calculated values agree quantitatively with the experimental data in both experiments, with an average relative error of $2.64 \%$ and $4.57 \%$ respectively.

\section{Case study}

According to variable information available in the literature, excellent granular sludge can be maintained under extreme conditions in Biobed ${ }^{\circledR}$ EGSB reactors, the bed height of such reactors often varies between 7 and $14 \mathrm{~m}$. Moreover, the settling velocity of the granules in a Biobed ${ }^{\circledR}$ EGSB reactor (Caldic Eurport, The Netherlands) is in the range of $60 \sim 80 \mathrm{~m} / \mathrm{h}$, and the granules are not washed out from the reactor even at a velocity of $15 \mathrm{~m} / \mathrm{h}$ (Zoutberg and de Been, 1997).

Kato et al. (1994) pointed out that well-formed granular sludge 3-4 $\mathrm{mm}$ in diameter can be maintained in EGSB reactors under high hydraulic loading conditions, and it has also been reported that the mean diameter of the granules in the Biobed ${ }^{\mathbb{B}}$ 


\begin{tabular}{|l|c|c|c|c|c|}
\hline \multicolumn{7}{|c|}{ TABLE 3 } \\
Changes in mean granule diameter in an a full-scale EGSB reactor \\
\hline Size distribution & $\mathbf{7 / 2 1 / 2 0 0 4}$ & $\mathbf{8 / 1 8 / 2 0 0 4}$ & $\mathbf{8 / 2 6 / 2 0 0 4}$ & $\mathbf{9 / 2 / 2 0 0 4}$ & $\mathbf{9 / 8 / 2 0 0 4}$ \\
\hline$>0.90 \mathrm{~mm}$ & 75.4 & 75.3 & 65.2 & 49.4 & 57.3 \\
\hline $0.63 \sim 0.90 \mathrm{~mm}$ & 19.1 & 22.2 & 31.4 & 41.6 & 36.7 \\
\hline $0.45 \sim 0.63 \mathrm{~mm}$ & 2.0 & 1.4 & 2.0 & 4.3 & 4.1 \\
\hline $0.315 \sim 0.45 \mathrm{~mm}$ & 3.4 & 1.1 & 1.3 & 4.8 & 1.9 \\
\hline Mean granule diameter/mm & 1.406 & 1.416 & 1.323 & 1.166 & 1.246 \\
\hline
\end{tabular}

EGSB reactor increased from 1.5 to $3.5 \mathrm{~mm}$ (mean density 1 $037 \mathrm{~kg} \cdot \mathrm{m}^{-3}$ ) during the one-year reactor operation (Gonzalez-Gil et al., 2001).

Hence $d_{\mathrm{p}}$ is $3,3.5,4 \mathrm{~mm}$ and $\rho_{\mathrm{p}}$ is $1040 \mathrm{~kg} \cdot \mathrm{m}^{-3}$ in our mathematical analysis, and the mean settling velocity is taken as $70 \mathrm{~m} / \mathrm{h}, \rho 1000 \mathrm{~kg} \cdot \mathrm{m}^{-3}$. Bed expansion data calculated by Eq. (12) are shown in Fig. 3.

As shown in Fig. 3, the calculated values of the bed expansion are very low when Vup is lower than $5 \mathrm{~m} / \mathrm{h}$, while the bed behaves as a static bed; the bed begins to expand when Vup exceeds $5 \mathrm{~m} / \mathrm{h}$; the value is approximately $20 \%$ when $V u p$ is around $10 \mathrm{~m} / \mathrm{h}$; the value is merely about $45 \%$ even when Vup is around $15 \mathrm{~m} / \mathrm{h}$.

Based on Fig. 3 , even if the original bed height of the EGSB reactor at Caldic is $14 \mathrm{~m}$ when Vup is around $10 \mathrm{~m} / \mathrm{h}$, the bedexpansion height is just $16.8 \mathrm{~m}$ which is close to the water level of the reactor $(17.3 \mathrm{~m})$. That may be the reason why the reactor can operate under such extreme conditions $(>10 \mathrm{~m} / \mathrm{h})$.

\section{Model application of the expansion model}

Data on the changes in mean granule diameter of a full-scale EGSB reactor with a working volume of $275 \mathrm{~m}^{3}$ (Yi-shui, Shandong province, China) during different operation time are shown in Table 3. The mean density of the granules is 1050 $\mathrm{kg} \cdot \mathrm{m}^{-3}$. Other data for simulation analysis are as follows: $\rho$ is $1000 \mathrm{~kg} \cdot \mathrm{m}^{-3}$, original bed height of the reactor is $5.4 \mathrm{~m}$.

The variations of the bed height during different period predicted by Eq. (12) are shown in Fig. 4.

As shown in Fig.4, the maximum bed height is around $10.6 \mathrm{~m}$ when Vup is about $4 \mathrm{~m} / \mathrm{h}$, which is close to the position of gas-solid-liquid (GSL) separator. Based on this figure, it can clearly be seen that the suitable Vup value necessary to preserve the stability in the reactor is around $4 \mathrm{~m} / \mathrm{h}$. Therefore the value of Vup applied in the EGSB reactor was controlled at around 4 $\mathrm{m} / \mathrm{h}$.

\section{Conclusions}

The model developed in this study is applicable to study the bed expansion in EGSB reactors, provided that appropriate values such as upward liquid velocities, physical parameters of the granules and wastewater (such as distribution of granule diameter, $\mu, \rho, \rho_{\mathrm{p}}$ ) are assigned. It can also be used to propose a suitable Vup value during different operation periods of an EGSB reactor. From a practical perspective, the findings of the present research have important implications on the design and operation of such reactors.

However, it should be noted that the impact of biogas production, the efficiency of the reactor, and other factors on bed expansion have not been considered. Therefore, they are not reflected in the proposed correlation. In short, further research is needed on the possible effects of these parameters, as well as the statistical significance of the results.

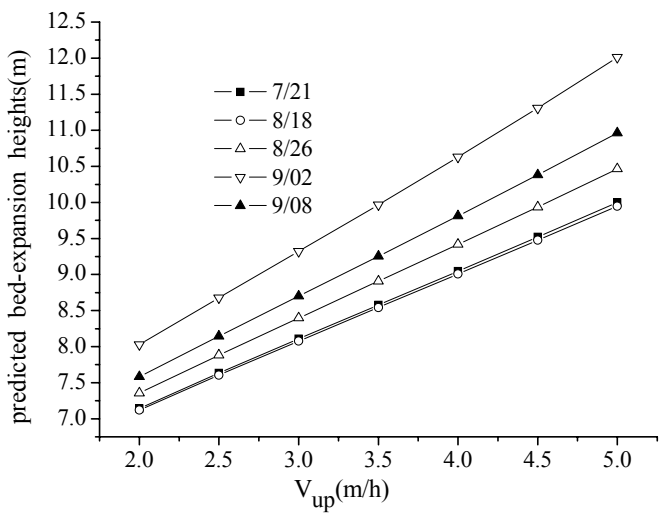

Figure 4

Variations of bed height with upward liquid velocity during different operation time

The following conclusions can also be drawn from this study:

- The sludge bed begins to expand when Vup exceeds $2 \mathrm{~m} / \mathrm{h}$; the bed expansion is above $20 \%$ when Vup exceeds $4 \mathrm{~m} / \mathrm{h}$ (Fig. 2)

- In Figs. 2, 3 and 4 it is shown that the corresponding Vup is around $3 \sim 7 \mathrm{~m} / \mathrm{h}\left(d_{\mathrm{p}}\right.$ range from 1 to $\left.2 \mathrm{~mm}\right)$ and the corresponding Vup is $10^{\mathrm{p}} \sim 15 \mathrm{~m} / \mathrm{h}$ ( $d_{\mathrm{p}}$ range from 3 to $4 \mathrm{~mm}$ ) when the bed expansion in EGSB reactors is controlled in the range of $20 \sim 40 \%$.

\section{Acknowledgements}

This study was financially supported by the China National 863 Program (2002AA601190) and the Education Office Foundation of the Shanxi Province (China) (06JK287), and the comments of two anonymous reviewers were gratefully appreciated.

\section{References}

FIELD J (2005) Anaerobic granular sludge bed technology [Online], http://www.uasb.org/discover/granules.htm (Accessed on September $\left.20^{\text {th }}\right)$

FRANKIN RJ (2001) Full scale experiences with anaerobic treatment of industrial wastewater. Water Sci. Technol. 44 (8) 1-6.

GONZALEZ-GIL G, LENS PNL, VAN AELST A, VAN AS H, VERSPRILLE AI, and LETTINGA G (2001) Cluster structure of anaerobic aggregates of an expanded granular sludge bed reactor. Appl. Environ. Microbiol. 67 (8) 3683-3692.

HU JC (2003) Theory and Technology of Anaerobic Biological Treatment. China Architecture Industrial Publishing Company. Beijing, China.

HULSHOFF POL LW (1989) The Phenomenon of Granular Anaerobic Sludge. Ph.D. Thesis, University of Wageningen, The Netherlands.

HULSHOFF POL LW; DE CASTRO LOPES SI, LETTINGA G and LENS PNL (2004) Anaerobic sludge granulation. Water Res. 38 (6) 1376-1389.

HWU CS, VAN LIER JB, LETTINGA GATZE (1998) Physicochemical and biological performance of expanded granular sludge bed 
reactors treating long-chain fatty acids. Process. Biochem. 33 (1) $75-81$.

JEISON D and CHAMY R (1999) Comparison of the behaviour of expanded granular sludge bed (EGSB) and upflow anaerobic sludge blanket (UASB) reactors in dilute and concentrated wastewater treatment. Water Sci. Technol. 40 (8) 91-97.

KATO MT, FIELD JA, VERSTEEG P and LETTINGA G (1994) Feasibility of expanded granular sludge bed reactors for the anaerobic treatment of low-strength soluble wastewaters. Biotechnol. Bioeng. 44 469-479.

LEITAO RC (2004) Robustness of UASB Reactors Treating Sewage under Tropical Conditions. Ph.D. Thesis, University of Wageningen, The Netherlands.

LENS PNL, BOSCHVANDEN ML, HULSHOFF POL LW and LETTINGA G (1998) Effect of staging on volatile fatty acid degradation in sulphidogenic granular sludge reactor. Water Res. 32 (4) 11781192.

LIU Y, XU HL, SHOW KY and TAY JH (2002) Anaerobic granulation technology for wastewater treatment. World J. Microbiol. Biotechnol. 18 99-113.

LIU YH, HE YL, LI YZ and YANG SC (2005) The settling characteristics and terminal velocity of granular sludge in UASB reactors. Acta Scientiae Circumstantiae. 25 (2) 176-179.

LIU YH, HE YL, LIU ZK (2005b) Measurement and study of settling velocity of granular sludge in anaerobic reactors. Industrial Water \& Wastewater (China) 36 (5) 45-48.

MARIN P, ALKALAY D, GUERRERO L, CHAMY R and SCHIAPPACASSE MC (1999) Design and startup of anaerobic fluidized bed reactor. Water Sci. Technol. 40 (8) 63-70.

MAHMOUD NIDAL, ZEEMAN G, GIJZEN H and LETTINGA G (2003) Solids removal in upflow anaerobic reactors, a review. Bioresour. Technol. 90 (1) 1-9.
NICOLELLA C, VAN LOOSDRECHT MCM, DI FELICE R and ROVATTI M (1999) Terminal settling velocity and bed expansion characteristics of biofilm-coated particles. Biotechnol. Bioeng. 62 (1) $62-70$.

PERRY RH and GREEN DW (1997) Chemical Engineers' Handbook ( $7^{\text {th }}$ edn.) McGraw-Hill, New York.

PIRES EC, HANISCH WS and ANDRADE MAN (2000) An original procedure for physical simulation of upflow anaerobic sludge blanket reactors. Bioprocess. Eng. 23 (4) 389-395.

RICHARDSON JF and ZAKI WN (1954) Sedimentation and fluidization. Trans. Inst. Chem. Eng. 3235 pp.

SEGHEZZO L, ZEEMAN G, VAN LIER JB, HAMELERS HVM and LETTINGA G (1998) A review: the anaerobic treatment of sewage in UASB and EGSB reactors. Bioresour. Technol. 65 (3) $175-190$.

SETIADI T (1995) Predicting the bed expansion of an anaerobic fluidised-bed bioreactor. Water Sci. Technol. 31 (9) 181-191.

SARAVANAN V, SREEKRISHNAN T R (2005) Hydrodynamic study of biogranules obtained from an anaerobic hybrid reactor. Biotechnol. Bioeng. 91 (6) 715-721.

WANG YC, ZUO JE and XIAO JH (2002) A study on characteristics of anaerobic granular sludge in an EGSB Reactor. China Biogas 20 (4) 3-7.

ZHANG XH (2004) Engineering of Water Pollution Control ( $2^{\text {nd }}$ edn.). China Metallurgy Industrial Publishing Company. Beijing, China.

ZOUTBERG GR and DE BEEN PETER (1997) The Biobed ${ }^{\circledR}$ EGSB (expanded granular sludge bed) system covers shortcomings of the upflow anaerobic sludge blanket reactor in the chemical industry. Water Sci. Technol. 35 (10) 183-188. 